ISSN: 0213-2079 - ISSN electrónico: 2386-3889

DOI: https://doi.org/10.14201/shhmo2020422145165

\title{
EL FLUJO DE MERCANCÍAS A LAS MISIONES JESUITAS EN EL NOROESTE DE LA NUEVA ESPAÑA
}

\section{The Flow of Products to the Jesuit Missions in the Northwest of New Spain}

\section{Bernd HAUSBERGER}

Centro de Estudios Históricos, El Colegio de México

bhausberger@colmex.mx

Fecha de recepción: 11/09/2020

Fecha de aceptación: 20/10/2020

RESUMEN: Este ensayo trata del sistema de abastecimiento de las misiones de la Compañía de Jesús en el noroeste de la Nueva España. Sostiene que los jesuitas participaron en la cultura material y de consumo en vías de globalización, lo que desencadenó un considerable y constante flujo de mercancías de todo el mundo del centro del virreinato de la Nueva España a la frontera. Esta situación se ilustra con los pedidos que los misioneros enviaron en 1712 a la Procuraduría de la orden. El suministro se pagó con la ayuda de la Corona y con la plata que las misiones ganaron mediante la venta de sus excedentes agropecuarios a los reales de minas de la región. De esta manera, se puede demostrar que las misiones estaban insertadas en un sistema comercial que movía bienes entre las diferentes partes del globo, pero también se apoyó en procesos de sustitución de importaciones que caracterizaron la globalización temprana.

Palabras clave: jesuitas; misiones; Nueva España; comercio; globalización temprana.

ABSTRACT: This essay deals with the supply system organized by the missions of the Society of Jesus in northwestern New Spain. It contends

Ediciones Universidad de Salamanca / @®@@ Stud. his., H. ${ }^{a}$ mod., 42, n. 2 (2020), pp. 145-165 
that the Jesuits participated in globalizing material culture and patterns of consumption, triggering a considerable and constant flow of goods from all over the world from the center of the viceroyalty of New Spain to the border. This situation is illustrated by the requests the missionaries sent in 1712 to the procurador general of the order. The supplies were paid with the help of the Crown and with the money that the missions earned selling their agricultural surpluses to the mines of the region. In this way, it can be shown that the missions were inserted in a commercial system that not only relied on moving goods between the different parts of the globe, but also on import substitution processes that characterized early globalization.

Keywords: Jesuits; missions; New Spain; trade; early globalization.

Este ensayo trata de un flujo mercantil particular, los envíos de abastecimiento a las misiones en el noroeste de México de la Compañía de Jesús. ${ }^{1}$ El sistema de suministros misionero fue construido durante el siglo XVII, aunque la mayoría de las fuentes de que disponemos son del XVIII. Sin embargo, podemos recurrir aquí a la figura de un «largo siglo XVII». En la Nueva España, y más en las regiones de frontera, los cambios que se suelen caracterizar como las reformas borbónicas se hicieron sentir solo poco a poco y, sobre todo, en la segunda mitad del siglo, durante el reinado de Carlos III (1759-1788) y a partir de la visita de José de Gálvez (1765-1771), siendo una de las medidas fundamentales precisamente la expulsión de los jesuitas en 1767. Esta identificación de la época de las reformas en el escenario americano con la segunda mitad del siglo XVIII ha sido cuestionado últimamente por varios autores ${ }^{2}$. En las regiones misioneras, un primer paso para reorganizar la frontera fue la visita de los presidios del Norte por el brigadier Pedro de Rivera, de 1724 y $1728^{3}$; y con la rebelión de los yaquis en 1740 empezó a deteriorarse el respaldo de la monarquía al sistema misional, mientras que el cambio de dinastía 40 años antes había pasado sin mayores consecuencias.

Este trabajo es el primer -y por lo tanto parcial- resultado de una investigación en proceso. Después de esbozar brevemente el contexto de las misiones, voy a

1. Agradezco el invaluable apoyo de Janet Lázaro en la organización de las fuentes para esta investigación.

2. P. ej. Sánchez Santiró (2013) y Pearce (2014). En el Pacífico hispánoamericano, Bonialian (2017: 12-20) ve el inicio de las nuevas reglas de juego en la cuarta década del siglo.

3. El resultado de la visita fue el primer reglamento para los presidios de la frontera norte, publicado en 1729 (Naylor y Polzer, 1989). 
BERND HAUSBERGER

EL FLUJO DE MERCANCÍAS A LAS MISIONES JESUITAS

EN EL NOROESTE DE LA NUEVA ESPAÑA

describir la organización y la naturaleza del envío de bienes al norte, para terminar con algunas consideraciones acerca de la relevancia del tema para la globalización temprana, ${ }^{4}$ o la mundialización, concepto usado por Serge Gruzinski (2004).

\section{LAS MISIONES}

Las misiones jesuitas, establecidas a partir de 1591 en el noroeste de la Nueva España y suprimidas en 1767, sirvieron de instrumento de colonización en un territorio alejado de las grandes civilizaciones mesoamericanas, donde las condiciones naturales eran difíciles y la fuerza de resistencia de las poblaciones autóctonas, semisedentarias o cazadores-recolectores, considerable. Como punto de partida de su labor les sirvió la minúscula Villa de San Felipe y Santiago de Sinaloa (hoy Sinaloa de Leyva), en la que los jesuitas fundaron un pequeño colegio y desde donde emprendieron la conversión de los grupos indígenas en el norte de Sinaloa. En las décadas siguientes, los ignacianos se establecieron entre los diversos pueblos de Sonora hasta el sur de la actual Arizona (mayos, yaquis, ópatas, eudeves, pimas), así como entre los tepehuanes y tarahumaras en la sierra de Durango y Chihuahua. En 1697, empezaron la difícil misión de Baja California y, en 1721, entre los coras de Nayarit. En 1702, para dar un dato preciso, los jesuitas administraban 100 misiones (casi todas formadas por un conjunto de entre dos y cuatro pueblos) entre los grupos indígenas nombrados, a las que en las primeras décadas del siglo XVIII se sumaron las de California y Nayarit, hasta llegar a 117 en $1748^{5}$.

La expansión misionera progresó en forma paralela con el avance de la administración real y la llegada de grupos laicos al noroeste, atraídos, sobre todo, por las expectativas despertadas por la minería. El respaldo militar fue prestado por una cadena de presidios establecidos a partir de 1601. Las tres iniciativas colonizadoras -la misionera, la minera y la administrativa-militar- estaban estrechamente relacionadas, aunque su respectivo peso variara de región en región. Las misiones estaban conectadas por una red de caminos con la Ciudad de Mexico, a través de la cual se realizó la relación con el sur del virreinato, y con las rutas transcontinentales al exterior ${ }^{6}$. Solo la península californiana tenía el privilegio de abastecerse por una vía marítima exclusiva.

El territorio de misiones se caracterizaba por la escasez de agua, la que era apremiante en unas partes de los desiertos de la costa y del norte de Sonora y de

4. Sobre el término de la «globalización temprana», véase Hausberger (2018: 21-38).

5. Testimonio, México, 12 de septiembre de 1775, Archivo General de la Nación, México (AGN), Misiones 22, fol. 81r-86v.

6. Sobre el papel de la Ciudad de México como punto de intersección de los ejes de comunicación novohispanos, véase Carmagnani (2012).

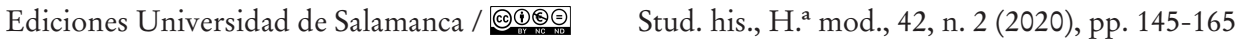


Chihuahua, así como en casi toda la Baja California. Por lo general, no se permitía una producción agrícola constante, salvo en los valles de los ríos. Los grupos étnicos con los que los ignacianos entraron en contacto, por lo tanto, nunca pudieron prescindir de actividades de caza, pesca y recolección, pero solo algunos dependían de ellas del todo. En esta situación, los jesuitas se empeñaron en organizar una producción agroganadera que garantizara la subsistencia y, de esta suerte, la permanencia de los indios en sus pueblos. La empresa misionera prosperaba, sobre todo, donde podía insertarse en tradiciones agrarias prehispánicas; en California, donde éstas no existían, los jesuitas enfrentaron enormes dificultades. Se vieron forzados a crear una organización económica especial, que dependía en alto grado de importaciones, inclusive de alimentos, que se financiaron con el rendimiento de un conjunto de haciendas en el centro de la Nueva España, el llamado Fondo Piadoso de la California (del Río, 1980; Hausberger, 2000: 485-502).

Pero también en las otras regiones, las misiones siempre necesitaban cosas que tuvieron que serles enviadas desde la Ciudad de México. Se trataba, sobre todo, de textiles para vestir cristianamente a los neófitos, objetos del culto, libros, papel, herramientas de hierro, tabaco y suplementos a las comidas del padre, como chocolate, azúcar, especias o vino (el que se necesitaba también en la misa). Su costo se cubrió por dos vías. Por un lado, cada misión recibía la llamada «limosna» del rey, de 250 pesos y, más en adelante, de entre 300 y 350 pesos (Hausberger, 2000: 380-385). Ocasionalmente, las misiones obtuvieron también donaciones privadas. Por otro lado, los jesuitas procuraron que la producción agroganadera de las misiones no solo asegurara la manutención de sus habitantes, sino que produjera un excedente que podían vender en la región. A partir de ahí, el sistema misional desarrolló una convivencia simbiótica con el sector minero. Las minas, aunque precarias, formaban los mercados principales para los productos de las misiones, a tal grado que dependían del suministro que los jesuitas les hicieran llegar, además de la mano de obra que procedía de los pueblos de misión (Hausberger, 1997a). Algunas misiones vendieron sus productos en centros mineros más lejanos, como Parral o la Villa de Chihuahua, lugares que experimentaron grandes bonanzas a partir de la cuarta década del siglo XVII y de la primera del XVIII, respectivamente. La producción de las minas del noroeste no era despreciable. Según los registros oficiales, entre 1761 y 1767, cada año salieron de la región alrededor de 2000000 pesos en oro y plata, aproximadamente el $4 \%$ de la producción total del virreinato. ${ }^{7}$ Una parte de estos metales pasaba por las manos de los jesuitas, y con ellos y la limosna del rey, en la Ciudad de México adquirían lo que se necesitaba.

7. Esto es una estimación basada en los datos recopilados en Hausberger (1997b), de los registros en la caja real de Durango, a los que se suman unos 215000 pesos registrados en Guadalajara.

Ediciones Universidad de Salamanca / @®@@ Stud. his., H. ${ }^{a}$ mod., 42, n. 2 (2020), pp. 145-165 
BERND HAUSBERGER

EL FLUJO DE MERCANCÍAS A LAS MISIONES JESUITAS

EN EL NOROESTE DE LA NUEVA ESPAÑA

\section{LAS MEMORIAS}

Así, mercancías de todo tipo llegaron a las misiones con las recuas de los caminos de tierra adentro (y a Baja California en un barco desde algún puerto del occidente de México). Para su envío, la Compañía de Jesús estableció un sistema cuyo coordinador era el padre procurador general en la Ciudad de México ${ }^{8}$. Cada año los misioneros le enviaron listas de lo deseado, las llamadas memorias. El procurador adquiría la mayor parte de los productos probablemente de los grandes comerciantes de la ciudad, aunque al respecto no he encontrado ninguna información, y los ponía en camino al norte. Para los objetos de culto puede ser que también se sirvieran de las compras realizadas por los procuradores enviados a Madrid y Roma en los mercados europeos, si bien también esto requeriría más investigación? ${ }^{9}$ Lo pedido llegaba a su destino, más o menos, un año después del envío de las memorias. Solo en 1755, se estableció una propia Procuraduría para las misiones, como oficina central de la administración financiera de las misiones. Ésta, en 1756, disponía de 57247 pesos $1 / 2$ real para cumplir con los pedidos de los misioneros. Alrededor de 27000 pesos provenían de la limosna del rey, 1400 de fundaciones privadas, y casi 29000 habían sido enviados por los misioneros. El gasto de este año sumó 55230 pesos 4 reales. La Procuraduría se quedó, por lo tanto, con una ganancia, pero enfrentaba una deuda antigua de las misiones con la Procuraduría General de 17630 pesos $^{10}$.

Por su regularidad, las memorias forman un cuerpo de documentación único que permite observar mediante una información seriada un circuito mercantil en el interior de la Nueva España y el desarrollo de las misiones como centros de consumo durante varias décadas. Muchas de las memorias están acompañadas de cartas en las que los misioneros justificaron sus deseos y necesidades, anunciaron el envío de plata o comentaron la llegada del envío anterior, expresando su grado de satisfacción o denunciando retrasos o mermas. Se puede mencionar que estas cartas que no son el tema de este estudio, son de interés especial, porque a veces son bastante francas, probablemente porque el procurador, prestaba un servicio a los misioneros, sin representar un nivel jerárquico superior. En algunas ocasiones también existen los registros de entrega de estos productos por parte de la Procuraduría a los respectivos arrieros o los recibos de los misioneros destinatarios. El

8. J. Gabriel Martínez-Serna (2009) lo llama procurador provincial (aunque en mis fuentes nunca aparece con este título), para distinguirlo de los procuradores que las provincias americanas cada tres años enviaron a Europa para representar sus intereses en Madrid y en Roma, y da un muy informativo resumen de la organización de los diferentes procuradores de la Compañía de Jesús; sobre los procuradores enviados a Roma, véanse Alcalá (2007) y Fechner y Wilde (2020).

9. Sobre estas compras, véase Alcalá (2007).

10. Razón y estado de la procuraduría de misiones, 1757, AGN, Jesuitas I-35, exp. 93, fol. 212r-212v.

Ediciones Universidad de Salamanca / @®@@ Stud. his., H. ${ }^{a}$ mod., 42, n. 2 (2020), pp. 145-165 
análisis de los productos listados en esta documentación da muchos elementos para conocer mejor la vida material y cotidiana de las misiones, su situación económica y su poder adquisitivo, así como sobre el comercio novohispano en general. No obstante, el trabajo con esta fuente enfrenta una serie de dificultades.

Es importante destacar que las memorias documentan un pedido, pero no lo que se ha enviado. No obstante, por los reiterados agradecimientos en las cartas de los padres se puede suponer que, por lo general, los productos solicitados les fueron enviados. Más frecuentes eran las quejas de que las cosas no llegaban bien. ${ }^{11}$ Tampoco se debe olvidar que las memorias y las limosnas enviadas no eran la única vía de abastecimiento de los misioneros, aunque les estaba prohibido comprar de comerciantes privados y, asimismo, vender parte de lo recibido fuera de las misiones (Polzer, 1976: 89, 123). «En todas las misiones», señaló el padre visitador general José de Utrera, «hay otras entradas o cambios de géneros por géneros o frutos por frutos» ${ }^{12}$. Así se llevó a cabo también el intercambio entre las misiones de Baja California y las de Sonora, especialmente del valle del río Yaquí, las que mandaron cereales a la península a cambio de mercancías que las misiones peninsulares recibían por su ruta de suministro marítimo (Hausberger, 2000: 496-498). El padre Marín de Benavides, por su parte, suplicó que no se le enviara azúcar «por tenerlo de cosecha en un trapiche de esta misión» ${ }^{13}$. En suma, las memorias ofrecen solo información parcial de las necesidades y del consumo de bienes traídos de afuera de la región a las misiones.

El análisis de las memorias guarda también una serie de problemas metodológicos más básicos, empezando con la identificación de los productos y la amplia gama de medidas usadas que dificulta la construcción de series cuantitativas. Muchas mercancías se enviaron con especificaciones, lo que hace necesario decidir si éstas se cuentan por separado o como un solo producto. Para dar un ejemplo, mientras que algunos padres pidieron simplemente «chocolate», otros querían «chocolate fino» y otros «chocolate ordinario». Finalmente, la documentación dista de ser completa. Hemos recopilado hasta ahora cerca de mil memorias entre los primeros años del siglo XVIII y 1767. Pero esto sería solo alrededor de la séptima parte de los pedidos enviados en el período. Como consecuencia, para trabajar con las memorias -no tan sorprendentemente- es imprescindible que los métodos cuantitativos se combinen con cualitativos.

11. P. Juan de San Martín al P. Proc. Gen. Cristóbal de Laris, Batuc, 2 de mayo de 1712, AGN, Jes. I-14, exp. 276. P. José López Rendón al H. Proc. Juan de Yturberoaga, Cariatapa, 24 de mayo de 1712, AGN, Jes. I-14, exp. 291.

12. Visita del P. Visit. Gen. José de Utrera, Guásabe, 22 de octubre de 1755, University of Texas, Austin, W. S. Stephens Collection, 67, p. 132.

13. P. Benavides al P. Proc. Gen. Cristóbal de Laris, Guazapares, 20 de abril de 1712, AGN, Jes. I-14, exp. 177. 
BERND HAUSBERGER

EL FLUJO DE MERCANCÍAS A LAS MISIONES JESUITAS

EN EL NOROESTE DE LA NUEVA ESPAÑA

\section{LAS MEMORIAS DE 1712}

Dada la multitud de memorias y los problemas metodológicos referidos, me limito aquí a las listas de los productos solicitados en 1712. De aquel año he encontrado un cuerpo de 36 memorias, procedentes de todas las provincias misioneras de la Compañía de Jesús, con la excepción de Baja California ${ }^{14}$. Uno de los padres, por enfermedad, no tenía la fuerza para pensar en un nuevo pedido y solicitó que se le enviara lo mismo que el año anterior. Para este propósito, mandó la lista de los productos que le habían llegado en que estaban registrados, por mano del padre procurador, los precios de cada partida, información valiosa a la que regresaremos más abajo ${ }^{15}$. Con la información de un solo año no puedo reconstruir ninguna dinámica en el tiempo, pero sí presentar un panorama general detallado.

En total, en 1712 se solicitaron aproximadamente 300 diferentes productos. Como todos los años, los padres pidieron objetos para las iglesias y la liturgia, libros, papel y herramientas. Pero empecemos con algunas cosas de uso personal de los padres, por ejemplo, con los 127 pares de zapatos que 24 de los 36 misioneros solicitaron de la Ciudad de México. Por lo menos 16 los pidieron por su uso propio y, como debían quedar bien, indicaron su talla. Requerían de entre ocho y once puntos, salvo uno, el padre José Neumann, el que los necesitó de 14 puntos. Debe haber sido el gigante entre los misioneros ${ }^{16}$. Hay algunos pedidos de calzado en mayor cantidad probablemente para distribuirlos entre los neófitos o los empleados que algunos misioneros ocupaban; en los casos en que se indicaba el tamaño, eran de entre ocho y doce puntos. Es decir, los padres entre los indios no sobresalían por su estatura, en contra de todo estereotipo.

Había 21 pedidos de sotanas. Solo tres de los misioneros la incluyeron en su memoria sin especificaciones. El padre José Javier de Caballero explicó que debía ser «de calamaco ${ }^{17}$ negro (que es durable) de vara y dos tercias de largo, y las mangas de media vara y tres dedos; las hombrilleras, de la manga al cuello, de una cuarta, y el cuello no muy ancho»; como alternativa, ofreció que se le remitiera «el género, doce varas, onza y media de seda negra, dos docenas de broches» ${ }^{18}$. Tres jesuitas deseaban su sotana «de género», uno «de género delgado», uno «de género para

14. Todas las memorias de este año se encuentran en AGN, Jes. I-14.

15. Certificación del P. Proc. Gen. Laris, México, 9 de febrero de 1712, AGN, Jes. I-14, exp. 215, con una nota del P. Francisco Medrano de Ibarra, Santiago, del 24 de septiembre de 1712.

16. Memoria del P. José Neumann, Caríchic, 1712, AGN, Jes. I-14, exp. 80.

17. «Tela de lana delgada y angosta, que viene de Portugal y otras partes, la qual tiene un torcidillo como gerga, y es a modo de droguete o espécie de el» (Diccionario, 1729: vol. 2).

18. Memoria, Guazave, 12 de mayo de 1712, AGN, Jes. I-14, exp. 233. 
tierra caliente» y uno «de picote ${ }^{19}$, o de otro género para tierra caliente» ${ }^{20}$. Dos la pedían «de paño», uno «de paño ordinario grueso», uno «de paño bueno», uno «de paño fino», uno «de paño de Cholula», uno «de paño de Castilla» y dos «de paño de Segovia». El padre Tomas de Solchaga quiso la suya «de calamaco, o picote, si hay paño de Castilla, mejor», pero añadió que «si puede ser de paño delgado de Holanda o del Imperio o de Baeza, será mejor». ${ }^{21}$ Queda manifiesto que los misioneros tenían claras ideas de lo que querían, y que no pocos preferían la tela de importación.

Los deseos de los jesuitas permiten ver cómo intentaban arreglarse la vida en su retiro, por ejemplo, con pequeños lujos para la cocina, alimentos y especias que no se daban en las regiones de la frontera. Por las distancias y las dificultades y costos del transporte no era practicable que se les enviaran alimentos básicos, con una excepción, por lo menos según los estándares de hoy: siete padres pidieron arroz, aunque en relativamente pequeñas cantidades, en total cuatro y media arrobas, o sea $51.75 \mathrm{~kg}^{22}$. Según Humboldt (1985, vol. 2: 328-331), en la Nueva España no se produjo arroz. Pero ya a finales del siglo XVI se cultivó en la zona del Pacífico, a dónde probablemente había llegado desde Manila (Machuca, 2013: 102); y un siglo y medio más tarde siguió presente en la costa de Acapulco y en la región de Tlapa (hoy en el estado de Guerrero) (Villaseñor y Sánchez, 1746: 190, 334). En el noroeste, el arroz no parece haber sido un producto tan raro. El hermano Juan de Esteyneffer (1732: 60, 174, 179, etc.), en su libro medicinal para las misiones, lo recomendó para varias dietas de enfermos, lo que hace sospechar que los padres no solo lo pedían para diversificar su dieta diaria, sino para tenerlo como reserva para los períodos de las frecuentes epidemias que azotaron a los pueblos de misión.

Había dos productos, que se consumían combinados, que casi todos los padres pedían en cantidades considerables: azúcar y chocolate. 32 de 36 memorias analizadas requirieron 137 arrobas y un tercio ${ }^{23}$ de azúcar, o sea $1667.5 \mathrm{~kg}$. Esto equivalía a $52.1 \mathrm{~kg}$ por misionero, para un consumo diario de 142 gramos. 31 jesuitas solicitaron 114 arrobas de chocolate, y once misioneros 25 arrobas de cacao, de ellos tres solo cacao (diez arrobas). Esto serían $1311 \mathrm{~kg}$ de chocolate y $287.5 \mathrm{~kg}$ de cacao. Sumando las dos cantidades, llegamos a un monto de $47 \mathrm{~kg}$ por misionario y 129 gramos por día.

19. «Tela áspera y basta que se fabrica de pelos de cabra» (Diccionario, 1737: vol. 5).

20. Memoria del P. Diego de Poza, San Juan Alaya, 28 de mayo de 1712, AGN, Jes. I-14, exp. 233.

21. Memoria del P. Tomás de Solchaga, Villa de Sinaloa, 4 de mayo de 1712, AGN, Jes. I-14, exp. 233.

22. Calculo con las siguientes equivalencias: 1 arroba $=11.5 \mathrm{~kg}, 1$ libra $=0.46 \mathrm{~kg}$ y 1 onza $=28.77$ gramos; 1 vara equivalía a $0.636 \mathrm{~m}$ (Barnes et al., 1981).

23. No se sabe con seguridad cuánto era un tercio. Clara Elena Suárez Argüello (1985: 97) ha reunido información según la cual vacilaba de entre 4 y 12 arrobas. Por motivos meramente pragmáticos he calculado con el valor promedio de 8 arrobas.

Ediciones Universidad de Salamanca / @®@@ Stud. his., H. ${ }^{a}$ mod., 42, n. 2 (2020), pp. 145-165 
Esto podría parecer un consumo muy alto, y el elevado gasto para estos productos reiteradamente fue criticado por los superiores de la orden (Polzer, 1976: 100, 103). Pero la recomendación del hermano Esteyneffer (1732: 491) de ingerir cierta pastilla en la mañana en ayunas «como una hora antes del chocolate», hace suponer que éste formaba parte del desayuno habitual de los misioneros. Además, según los padres, fue necesario servir chocolate, con mucho azúcar, a las visitas y a los viajeros distinguidos que pasaban por las misiones (funcionarios reales, capitanes de presidios, mineros, jesuitas vecinos). Desde su misión de Tecoripa, Sonora, en 1737, el padre Felipe Segesser (1886: 66-67) le escribió a su hermano en Suiza que «durante los tres años de mi estancia no me he quedado cinco días sin huéspedes. Cada uno trae un saludo o una carta de un fulano, si bien aquel a veces no sabe nada de eso, y quiere tomar su chocolate». Otros aseguraron que el chocolate no era solo un vicio, sino que alimentaba a los misioneros que habían alcanzado una «edad, donde ya los tasajos de vaca y tortillas aprovechan poco» ${ }^{24}$.

Lo que observamos aquí son la cultura material y los patrones de gusto y consumo que se estaban estableciendo en el contexto de la globalización temprana y en el que las misiones y, sobre todo, los misioneros participaban plenamente. En el mundo occidental, la popularidad del azúcar y de las bebidas estimulantes (cacao, café, y té) crecían juntas (Stobart, 2013); y en las misiones de 1712 esto queda casi perfectamente ilustrado con las cantidades similares de azúcar y chocolate que fueron importadas por los jesuitas. Es notable también que los padres de origen centroeuropeo, José Neumann, Daniel Januske y Marcos Antonio Kappus, no se distinguían de sus colegas hispanos (europeos o criollos). Por cabeza pedían $61.3 \mathrm{~kg}$ de chocolate y $51.75 \mathrm{~kg}$ de azúcar, este último solo entre Neumann y Januske, porque Kappus no pedía azúcar; probablemente tuvo otra fuente de abasto. Solicitaban más chocolate que el promedio, lo que se explicará porque Januske y Kappus trabajaban en Sonora, donde estaban las misiones más ricas. Se plantea la pregunta de si habían adoptado los gustos vigentes en el espacio de su trabajo o si, por lo menos en cierta medida, continuaban costumbres adquiridas ya en Europa.

Para satisfacer sus gustos, los jesuitas debían recurrir a circuitos transregionales, e incluso transcontinentales. En cuanto al azúcar lo más probable es que provenía de sus propias haciendas especializadas en el cultivo de la caña en el centro del virreinato, como la de Xochimancas. En cuanto al chocolate y el cacao, las memorias contienen diferentes especificaciones. Por lo general, se pide chocolate «fino» o «rico», y solo el padre Kappus solicitó tanto «chocolate fino» como «chocolate ordinario». Según las preferencias de la época, se puede sospechar que este último era cacao de Guayaquil, en la costa de Ecuador, que fue considerado más fuerte y amargo

24. P. Juan Bolton al P. Proc. Gen. Cristóbal de Laris, San Ignacio, 14 de mayo de 1713, AGN, Jes. 1-14, exp. 282. 
(MacLeod, 1973: 241). En los once pedidos de cacao, en cinco ocasiones se detalló el tipo deseado: tres misioneros querían cacao de Guatemala y Soconusco, uno de Caracas, y uno de Guatemala, Caracas o Maracaibo (pero ninguno de Guayaquil).

Viendo otros alimentos y golosinas, el panorama de la inserción de las misiones en extensos circuitos comerciales se confirma, aunque en cuanto a la mayoría de los ejemplos que a continuación presentaré, el origen de los productos es más bien probable, no siempre del todo seguro. Llegaron productos de diferentes partes de la Nueva España, como el ya mencionado arroz, dos pesos de chile ancho, 1 libra de tamarindo, 2 mazos de vainilla y 50 manojos y 2 tercios de tabaco (más de 100 $\mathrm{kg})^{25}$. Desde la capitanía general de Guatemala se trajeron las ya referidas cantidades de cacao, pero también 2 y media libras de añil y 4 libras de achiote, que se usaba, sobre todo, para saborizar el chocolate (MacLeod, 1973: 251).

Es de suponer que las 3 botijas de aceite, las 3 libras de alcaparras y las 14 libras 13 onzas $(6.8 \mathrm{~kg})$ de azafrán que los misioneros solicitaron habían sido importadas desde España. Los 6 frasquitos y el cajoncito de santos óleos para los 14 pueblos del rectorado de San Francisco Javier en Sonor ${ }^{26}$ probablemente también eran aceite español, aunque a la Nueva España, para estas fechas, también llegaba aceite de oliva de Perú (Bonialian, 2017: 9). De Asia llegaron algunas especias: 42 libras (19,32 kg) de canela, de Ceilán (Sri Lanka), para 22 padres, o sea 878 gramos por cabeza; y 9 libras 14 onzas de clavo y 6 pesos de nuez moscada de las islas del sureste de Asia neerlandesa. Además, 21 misioneros solicitaron 34 y media libras $(15.87 \mathrm{~kg})$ de pimienta. Presumo que se trataba de la pimienta negra asiática, pero también podía ser la pimienta de Tabasco que es más bien aromática-dulce (Machuca, 2013: 104).

Alguna estima gozaron varios productos que originalmente eran del Viejo Mundo, pero ya se producían en la Nueva España, como el jengibre (ajenjibre, 3 libras y 4 onzas) (Machuca, 2013: 103); el ajonjolí (6 libras), cultivado en Veracruz (Villaseñor y Sánchez, 1746: 259, 265); el anís (8 libras), en la jurisdicción de Izúcar (Villaseñor y Sánchez, 1746: 361); la cañafístula (6 libras y 4 reales), una planta medicinal asiática, cuyo intensivo cultivo en Colima por 1622 ha señalado Paulina Machuca (2013: 103-104)27.

25. En 1786 se fijó el manojo de tabaco en 17.5 onzas (Carpio-Penagos, 2014: 197).

26. Memoria del P. Daniel Januske, Oposura, 21 de marzo de 1712, AGN, Jes. I-14, exp. 276.

27. Según wikipedia otro nombre de la cañafístola es ojasén, producto que también aparece en mis listas; https://es.wikipedia.org/wiki/Cassia_fistula (consultado 14 de mayo de 2020). Pero ojasén o hoja sen, originalmente es la sena alexandrina; https://es.wikipedia.org/wiki/Senna_alexandrina (consultado 14 de mayo de 2020). Ojasén, 3 libras, 6 onzas más un peso (1,55 kg más un peso); al buscar en internet por ojasén (hojasen), se encuentran varias plantas, de uso medicinal (Esteyneffer, 1732: 231, 298), como Senna alexandria, Senna confinis, Cassis fistula (cañafístula) o Flourensia cernua, así que es 


\section{BERND HAUSBERGER \\ EL FLUJO DE MERCANCÍAS A LAS MISIONES JESUITAS \\ EN EL NOROESTE DE LA NUEVA ESPAÑA}

Finalmente se pidió vino, para la misa. Pero, aunque como tal era imprescindible para la liturgia, solo lo pidieron tres padres en una cantidad muy reducida. Es de suponer que se trataba de vino español (probablemente no todo para la misa) y que los otros misioneros se abastecían regionalmente, de la vendimia de las misiones de Baja California o del Colegio jesuita en Parras (Hausberger, 2000: 489-490; Corona Páez, 2010).

Las mercancías más importantes que llegaron al noroeste a través del sistema de abastecimiento de las misiones eran los tejidos que se usaban ante todo para la vestimenta cristiana de los neófitos. Se identifican cerca de 30 tipos, algunos con variedades, dependiendo de cómo se cuenten. Presento un pequeño resumen de los más solicitados:

Sayal28: 1939 varas (1621 metros), para 23 misiones; de ellas, 1050 varas de sayal ancho (260 de Cuautitlán), 100 varas de sayal angosto y 789 de sayal (50 varas de Texcoco).

Ruan $^{29}: 438$ varas y 4 piezas, para 25 misiones; de ellas, 115 varas de ruan, 285 varas de ruan florete ${ }^{30}$ y 28 varas de ruan de China.

Crea ${ }^{31}: 247$ varas (207.3 metros), para 21 misiones; de ellas, 130 varas de crea, de las que 38 varas fueron pedidas como «crea de León» (Lyon, Francia); 118 varas de crea ancha, de ella 47 varas de «crea de León».

Bayeta: ${ }^{32} 241$ varas (201.5 metros), más una y media pieza de bayeta y media pieza de bayeta ancha, para 16 misiones; de ellas, 66 varas y las dos piezas de Puebla, y 8 varas de Castilla.

Paños ${ }^{33}: 237$ varas (198.1 metros) y 17 piezas, para 19 misiones; de ellas, 12 piezas de paño de rebozo de la Sierra Huasteca, 1 pieza de paño común, 1 y media

difícil saber de cuál exactamente se trataba. Todas crecían en la Nueva España, aunque en parte fueron introducidas desde Asia.

28. «Tela mui basta, labrada de lana burda» (Diccionario, 1738: vol. 6).

29. «Especie de lienzo fino, llamado assí por el nombre de la Ciudad de Ruán en Francia, donde se texe y fabrica» (Diccionario, 1737: vol. 5).

30. Florete, «lienzo o tela entrefina de algodón» (RAE); de adjetivo, «se aplica al papel de primera suerte, más blanco y lustroso» (Diccionario, 1732: vol.3).

31. «Cierto género de tela o lienzo, que no es de los más finos ni de los más toscos, que sirve para hacer camísas, sábanas y otras cosas. Llámase comunmente Leona, porque viene de León de Fráncia» (Diccionario, 1729: vol. 2).

32. «Tela de lana mui floxa y rala, de ancho de dos varas lo mas regular, que sirve para vestídos largos de Eclesiásticos, mantillas de mugéres, y otros usos» (Diccionario, 1726: vol. 1).

33. «La tela de lana de varias estofas, que sirve para vestirse y otros usos. Segun su calidad, fuertes o fábrica toma varios nombres. [...] Por extensión se llama qualquier texido de seda, lino o algodón» (Diccionario, 1737: vol. 5). 
pieza y 130 varas de paño fino, media pieza de paño fino dieciocheno ${ }^{34}$; 45 varas de paño de Cholula y 50 varas de paño mexicano.

Palmilla ${ }^{35}: 120$ varas (100.3 metros) y dos y media piezas, para 13 misioneros; de ellas 60 varas y las 2 y media piezas de paño palmilla (12 varas de paño palmilla mexicano).

Frazadas $^{36}$ : 235 piezas, para 16 misiones; de ellas, 42 frazadas mestizas, 86 frazadas pastoras, 24 frezadillas y 83 frazadas, de ellas 25 de Texcoco.

Mantas: más de 100, para 32 misiones; de ellas, 28 y «algunas», mantas de Campeche, 46 y «algunas» mantas de patíes (o patíes enteros) ${ }^{37}, 20$ mantas de Puebla (de ellas, una manta fina), cuatro de Villalta o Nexapa y dos «mantas moras».

Bretañas $^{38}: 33$ piezas, para 17 misiones; de ellas 13 piezas de bretaña y 17 piezas de bretaña ancha, más 3 varas de bretaña ancha.

Es imposible saber con seguridad (o adivinar con algún fundamento) en cada caso de qué tipo de tejido se trataba (no obstante, las descripciones de la época que he puesto en las notas) y dónde se fabricaron estas telas. En el listado antecedente se ve que con cierta frecuencia se solicitaron explícitamente productos de una procedencia concreta. También lo hemos podido observar con las sotanas, y se presenta también con los textiles solicitados en cantidades menores. El padre José Javier Caballero quiso seis varas de "coleta de Francia vetada negro y blanco». ${ }^{39}$ Los padres Luis Javier Velardo y Juan de San Martín pidieron cada uno una pieza de raso de China. ${ }^{40} \mathrm{El}$ padre Tomás de Solchaga necesitó cuatro varas de tafetán,

34. Paño «que tiene una urdimbre de dieciocho centenares de hilos» (RAE).

35. «Cierto género de paño, que particularmente se labra en Cuenca» (Diccionario, 1737: vol. 5).

36. «La manta pelúda que se echa sobre la cama» (Diccionario, 1726: vol. 1).

37. Los misioneros escriben «patios», pero se debe haber tratado del término maya "patí», «una manta de algodón tosco» (García Bernal, 1972: 126) o «[...] una manta o colcha tejido a mano, producto de la industria algodonera regional, en Yucatán» (Santamaría, 1983: 817).

38. "Cierto género de lienzo fino, que se fabrica en la Província de Bretaña, de quien tomó el nombre. Hai dos espécies, una ancha, y otra mas angosta» (Diccionario, 1726, vol. 1).

39. Memoria, Guazave, 12 de mayo de 1712, AGN, Jes. I-14, exp. 233.

40. «Tela de seda lustrosa, de más cuerpo que el tafetán, y menos que el terciopelo. Fórmase levantando los lizos para que texa la trama, solo de ocho en ocho lizos, que es texiendo solo la octava parte del urdimbre, quando en el tafetán, mantos, lienzos y otras telas endebles, trabaja todo el urdimbre por levantar los lizos uno sí, y otro, alternativamente, como en el raso solo trabaja la octava parte del urdimbre, queda esta con su lustre y la recoge el peine, con que toma cuerpo la tela» (Diccionario, 1737, vol. 5), Memoria, Papigochic, 12 de junio de 1712, AGN, Jes. I-14, exp. 294; Memoria, Batuc, 17 de marzo de 1712, AGN, Jes. I-14, exp. 276.

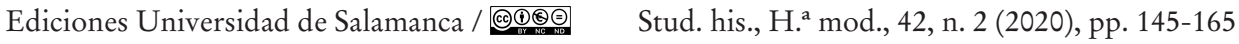


de España. ${ }^{41}$ No obstante, no podemos saber, si el procurador respetó estos deseos o prefirió comprar una variedad más barata.

El nombre de algunas telas se deriva de un lugar de producción, como el ruan y el cambray ${ }^{42}$ (se pidieron 4 varas) de las ciudades de Ruan y Cambray, en Francia, y las bretañas de la región francesa de la Bretaña. Pero obviamente los contemporáneos solían desconocer la vinculación geográfica de estas denominaciones (Perissionotto, 1997: 467) y muchas de ellas se habían convertido en designaciones de ciertos tipos de tela y no permiten deducir el verdadero origen del producto. En algunos casos se puede suponer un origen asiático como en el caso de la «elefanta» (3 piezas) ${ }^{43}$, del chamelote ${ }^{44}$ (12 varas) o de la sayasaya (6 varas y 4 piezas), una tela china barata, muy usada en las Filipinas (Sales Colín, 2000: 163). Una duda general la provoca el pedido de «fileles» por parte del padre Juan de San Martín. El Diccionario de autoridades (1729, vol. 2) registra «fileli» como «tela de lana delgada, mezclada con hierba, que se solía traher de Berberia», pero el padre San Martín explicó que eran de algodón y de China y que los quería para sábanas para la época fría ${ }^{45}$. Así, por lo menos en este caso, los misioneros perecen haber usado los nombres con un significado diferente del que en Madrid se les asignó.

Pero en suma, la mayoría de los textiles con toda probabilidad vino de la Nueva España, tanto de los obrajes, como el sayal y los paños, como de las comunidades indígenas del centro y sur de México, a los que se extraían mantas y patíes a través del reparto forzoso de mercancías o el tributo para distribuirse desde Puebla o Yucatán en todo el virreinato hasta el extremo norte (García Bernal, 1972: 126-133; Pastor, 2002: 241-243).

Como advertimos, se pidieron muchos productos más, como 174 cuchillos de diferentes tipos (para 10 padres), probablemente de hierro vizcaíno; 30 pares de calcetas (8 padres); 43 pares de medias (11 padres); 71 sombreros (12 padres), de ellos 4 religiosos y 6 «entrefinos»; 32 arrobas y 2 libras (269 kg, para 17 padres) de cera para velas, en parte ya labrada, y de ellos 1 arroba y dos libras de China, aunque grandes cantidades de cera fueron extraídos de los indios del sur de México, a través de reparto forzoso (García Bernal, 1972: 126-133); 25 y media libras, 6 madejas y 2 mazos de diferentes tipos de hilo (para 19 padres), entre ellos 4 y media

41. Memoria del P. Tomás de Solchaga, Villa de Sinaloa, 4 de mayo de 1712, AGN, Jes. I-14, exp. 233.

42. "Cierta tela de lienzo mui delgada y fina, que sirve para hacer sobrepellices, pañuelos, corbatas, puños y otras cosas. Dixose assí por haver venido de la Ciudad de Cambráy, donde por lo regular se fabrica» (Diccionario, 1729, vol. 2).

43. El P. Neumann pidió un pieza de «elefanta o ruan de China»; Memoria del P. Neumann, Caríchic, 1712, AGN, Jes. I-14, exp. 80.

44. «Tela texida de pelo de camello» (Diccionario, 1729, vol. 2).

45. Memoria, Batuc, 17 de marzo de 1712, AGN, Jes. I-14, exp. 276. 
libras de «hilo de muñequilla» de Flandes ${ }^{46} ; \mathrm{y}$ «polvos» (presumo que se trataba de medicamentos): 32 libras de polvos lavados, de ellas 6 de Sevilla (para 10 padres); 6 libras de polvos de La Habana, 8 pañuelos de polvos de Malinalco y 2 cajoncitos de "polvos de hueso de China», que necesitó el padre Tomás de Solchaga. ${ }^{47}$ Finalmente podemos mencionar 10 resmas y dos manos de papel, que serían 5050 pliegos (para 17 padres; casi 300 pliegos por persona). Papel llegó a la Nueva España desde Europa y desde China, pero por lo que se ve en los archivos, los misioneros no utilizaban el fino papel chino; y, en 1712, dos resmas se solicitan explícitamente como «papel de Génova».

Finalmente quiero echar un vistazo al valor de estos pedidos, para lo cual sirve la información de los precios cobrados al padre Francisco Medrano de Ibarra en 1712.

Los datos de la tabla ofrecen un panorama parcial, pues solo abarcan 23 de los productos más solicitados, de un total de alrededor de 300 , y esto únicamente de 36 misiones, de un total de alrededor de 100 . Además, el precio indicado en la fuente a veces valía para un cierto tipo de producto, lo que solo se ha podido tomar en cuenta de forma parcial. Pero con todo, muestra algunas cosas notables. En primer lugar, corrobora que el gasto mayor de las misiones recaía en los textiles (1582 p $6 \mathrm{rr}$ ) y en el conjunto del chocolate y el cacao (1 674 p 6 rr). Estas prioridades se ratifican, si tomamos en cuenta que los importes referidos no incluyen el costo de la multitud de tejidos pedidos en cantidades menores, como tampoco las ropas ya hechas (sotanas, sobrerropas, calzones, medias, camisas); en el otro rubro habría que considerar que gran parte del azúcar, de la canela, del achiote y de la vainilla se usaba para saborizar el chocolate.

TABLa 1. Los precios de algunos productos enviados a las misiones, en 1712

\begin{tabular}{|l|c|c|c|}
\hline \multicolumn{1}{|c|}{ Producto } & Precio por unidad & $\begin{array}{c}\text { Cantidad pedida } \\
\text { en las 36 memorias } \\
\text { de } 1712\end{array}$ & $\begin{array}{c}\text { Costo total } \\
\text { del pedido }\end{array}$ \\
\hline Azafrán & $4 \mathrm{p} 4 \mathrm{rr} /$ libra & 14 libras 13 onzas & $66 \mathrm{p} 5 \mathrm{rr}$ \\
\hline Azúcar & $3 \mathrm{p} 6 \mathrm{rr} /$ arroba $* *$ & 145 arroba & $543 \mathrm{p} 6 \mathrm{rr}$ \\
\hline
\end{tabular}

46. Nemnich (1816: 135) identificó el «hilo de muñequilla» con «fil de mulquinerie» de Flandes, y de hecho el padre Manuel de Ordaz pidió «hilo de Flandes o muñequilla»; Memoria del P. Visit. Ordaz, Sinaloa, 13 de mayo de 1712, AGN, Jes I-14, exp. 233. Perissionotto (1997: 459), con documentación de la Alta California de finales del siglo XVIII, menciona «hilo de muñequilla» de Córdoba, probablemente Córdoba en España.

47. Memoria del P. Tomás de Solchaga, Villa de Sinaloa, 4 de mayo de 1712, AGN, Jes. I-14, exp. 233.

Ediciones Universidad de Salamanca / @@ Stud. his., H. ${ }^{a}$ mod., 42, n. 2 (2020), pp. 145-165 
BERND HAUSBERGER

EL FLUJO DE MERCANCÍAS A LAS MISIONES JESUITAS

EN EL NOROESTE DE LA NUEVA ESPAÑA

\begin{tabular}{|c|c|c|c|}
\hline Bayeta & $7 \mathrm{rr} / \mathrm{vara}$ & 241 varas & 210 p $7 \mathrm{rr}$ \\
\hline Cacao & 7 p 6 rr / arroba & 25 arroba & 193 p 6 rr \\
\hline Calcetas & $1 \mathrm{p} / \mathrm{par}$ & 30 pares & 30 pe \\
\hline Canela & $4 \mathrm{p} 4 \mathrm{rr} /$ libra & 42 libras & $189 \mathrm{p}$ \\
\hline Cera bujía & $7 \mathrm{rr} /$ arroba & $32 @ 2$ libras & $28 \mathrm{p}$ \\
\hline Chocolate & $13 \mathrm{p} /$ arroba $* * *$ & 114 arroba & $1482 \mathrm{p}$ \\
\hline Clavo & $71 / 2 \mathrm{rr} /$ libra & 9 libras 14 onzas & $9 \mathrm{p} 2 \mathrm{rr}$ \\
\hline Crea & $6 \mathrm{rr} / \mathrm{vara}$ & 247 varas & $185 \mathrm{p} 2 \mathrm{rr}$ \\
\hline Frazadas & $7 \mathrm{rr} /$ piezas & 235 & 205 p 5 rr \\
\hline Hilo & $28 \mathrm{rr} /$ libra & $25 \frac{1}{2} 2$ libras & $89 \mathrm{p} 2 \mathrm{rr}$ \\
\hline Jengibre & $4 \mathrm{rr} /$ libra & 3 libre 4 onzas & $2 \mathrm{p} 1 \mathrm{rr}$ \\
\hline Mantas de Puebla & $11 \mathrm{p} / \mathrm{pieza}$ & 20 & $220 \mathrm{p}$ \\
\hline Palmilla & $10 \mathrm{rr} / \mathrm{vara}$ & 120 varas & $150 \mathrm{p}$ \\
\hline Papel & $2 \mathrm{rr} / \mathrm{mano}$ & 10 resmas 2 manos & $50 \mathrm{p} 4 \mathrm{rr}$ \\
\hline Pimienta & $6 \mathrm{rr} /$ libra & 34 y media libra & $25 \mathrm{p} 7 \mathrm{rr}$ \\
\hline Ruan & $81 / 2 \mathrm{rr} / \mathrm{vara}$ & 115 varas & $122 \mathrm{p} 1 \frac{1}{2} \mathrm{rr}$ \\
\hline Ruan de China & $4 \mathrm{rr} /$ vara & 28 varas & $14 \mathrm{p}$ \\
\hline Sayal & $2 \mathrm{rr} / \mathrm{vara}$ & 1939 varas & 484 p 6 rr \\
\hline Sombreros & $6 \mathrm{rr} /$ pieza $* * * *$ & 71 & $53 \mathrm{p} 2 \mathrm{rr}$ \\
\hline Sotana & 34 pesos $*$ & 21 & $714 \mathrm{p}$ \\
\hline Zapatos & 1 peso & 127 & $127 \mathrm{p}$ \\
\hline
\end{tabular}

"Sotana de paño de Segovia ** azúcar blanca *** Chocolate fino $* * *$ sombreros entrefinos Fuente: Los precios son de la certificación del P. Proc. Gen. Laris, México, 9 de febrero de 1712, AGN, Jes. I-14, exp. 215.

Ahora, partiendo de la hipótesis de que la Procuraduría pasaba los productos a los misioneros a precio de coste y que la suma total de 5196 pesos 1 real acreditada en la tabla constituye solo una pequeña parte del total, sin incluir los fletes, resulta una inversión considerable que los jesuitas realizaron cada año en el envío de mercancías al Noroeste. Hemos mencionado arriba que en 1756 la Procuraduría General de Misiones gastó 55230 pesos en el abastecimiento misionero, y no hay razón para pensar que en 1712 la suma haya sido mucho menor. Cuando en 1737, para tomar un ejemplo, Rodrigo Antonio de Neira, comerciante de la Ciudad de

Ediciones Universidad de Salamanca / @®@@ Stud. his., H. ${ }^{a}$ mod., 42, n. 2 (2020), pp. 145-165 
México, y Miguel Antonio de Boada formaron una compañía, con una duración de tres años, reunieron un capital de 20000 pesos (es decir, 6667 pesos por año), en «géneros de mercaderías y poner tienda de ellas en la Nueva Vizcaya, Villa de San Felipe el Real de Chihuahua o provincia de Sonora» ${ }^{48}$. En 1702, el capitán Alonso de Valenzuela de Quesada, mercader de Guadalajara, envió a Pedro Ortiz, vecino de Huatulco, con 80 arrobas de chocolate y 84 arrobas de azúcar a Sonora, para que allí lo vendiera dentro de un año «a 10 pesos en plata la libra de chocolate, con libra de azúcar, que es el corriente de dicha provincia». No sabemos el costo de adquisición que tuvo Valenzuela de Quesada, pero se esperaban ingresos de 20000 pesos, con lo que había que pagar el flete y el trabajo de su agente (para lo cual calculó 500 pesos $)^{49}$. Este caso, además de que confirma que el monto de los envíos anuales de la Procuraduría a las misiones constituía una empresa formidable, en el contexto del comercio con la lejano Norte de la época, nos proporciona una clara prueba de la ventaja que significó para las misiones el abastecerse desde la Ciudad de México. Pues, si calculamos con los precios indicados en la tabla, y un costo de 10 reales para el transporte de una $\operatorname{arroba}^{50}$ ( 0.4 reales/libra) se da un precio de más o menos 5.8 reales por 1 libra de chocolate fino con una libra de azúcar, es decir considerablemente menos de los 10 pesos ( 80 reales) que cobraba el comercio laico en la frontera, que probablemente, tomando en cuenta la ubicación de los dos actores en Huatulco y Guadalajara, se refería al chocolate más barato de Guayaquil. A esta reducción nominal del $92.8 \%$ habría que añadir que los misioneros evitaron todos los manipuleos de los precios que en Sonora se practicaron debido a que en la zona apenas circulaba moneda y se pagaba en plata pasta, cuya equivalencia en reales se calculaba de forma más bien arbitraria (Hausberger, 2014). Esta garrafal diferencia quizás aporta un elemento para entender porqué a los laicos les apetecía tanto visitar a los misioneros y tomarse con ellos su chocolate fino, de otra manera casi inalcanzable para ellos.

A los padres, los precios no les eran indiferentes. El padre Marcus Antonius Kappus, por ejemplo, pidió una pieza y 50 varas de ruan florete, pero solo «si su valor no pasa de 7 u 8 reales la vara ${ }^{51}$. En 1715, el mismo Kappus se enteró en Sonora de que el galeón de Manila de 1715 había traído 5000 fanegas de chitas de China, inmediatamente se dirigió al procurador para que le consiguiera hasta doce

48. Escritura de compañía, México, 11 de marzo de 1737, Archivo General de Notarías de la Ciudad de México, Fondo Antiguo, Notaría 73, Juan Francisco Benítez Trigueros, vol. 512, f. 76r-77v.

49. Recibo, Guadalajara, 2 de octubre de 1702, Archivo de Instrumentos Públicos de Guadalajara, Notaría Antonio de Ayala, libro. 1, f. 153v-154r.

50. Certificación del P. Proc. Gen. Laris, México, 9 de febrero de 1712, AGN, Jes. I-14, exp. 215

51. Memoria del P. Kappus, Arivechi 11 de mayo de 1712, AGN, Jes. I-14, exp. 293.

Ediciones Universidad de Salamanca / @@ Stud. his., H. ${ }^{a}$ mod., 42, n. 2 (2020), pp. 145-165 
piezas de este género para su sacristía ${ }^{52}$. Aunque esto puede haber significado cierto lujo, hay que estar consciente de que desde Manila siempre llegó también mercancía muy barata, más barata que la que la competencia española en el Atlántico pudo ofrecer, hecho en el que tanto ha insistido Mariano Bonialian (2016: 665-667). En nuestra pequeña tabla, tal situación se confirma con el detalle que, en 1712, el ruan costó 8 y medio reales la vara, y el ruan de China solo 4 reales. Aunque puede ser que esta diferencia de precio expresa una diferencia de calidad, queda el hecho que la identificación de la mercancía asiática con productos de lujo no es aplicable en los mercados hispanoamericanos.

\section{CONCLUSIÓN}

Lo que hemos descrito hasta aquí ilustra algunas características que definen la globalización temprana.

A partir del siglo XVI, el globo estaba conectado por un conjunto de circuitos comerciales en el que interactuaban relaciones de diferentes escalas, de lo local hasta lo transcontinental, y se intercambiaban productos orientales de lujo y productos manufacturados de todo tipo, por un lado, y metales preciosos, como medio de pago, por el otro. El hecho que esto se observe en una región periférica, en términos de la penetración colonial del Occidente, subraya la fuerza de los fenómenos que estamos observando. Es verdad, hemos presentado una práctica realizada dentro del marco organizativo de la Compañía de Jesús, una organización con un sistema administrativo y de información que abarcaban cuatro continentes (Friedrich, 2011). Sin embargo, los inventarios de los que disponemos sobre el comercio laico, muestran el mismo panorama ${ }^{53}$. Se podría extrañar a África en esta historia de la frontera globalizada, mas no faltaban esclavos negros en las misiones jesuitas, aunque nunca los había en números considerables ${ }^{54}$.

52. P. Kappus al P. Proc. Gen. Juan de San Martín, Arivechi 1715 Juni 26, Archivo Histórico de la Provincia Mexicana de la Compañía de Jesús, n. 1726. "Chita» originalmente era un tejido de algodón (calicó) estampado (Nassu, 2016: 347-349).

53. Véase, por ejemplo, el inventario de los géneros que dejó el capitán Jacinto Dávila Aguirre, mercader en el real de San Juan Bautista, Sonora, 26 de noviembre de 1659, AGN, Archivo Histórico de Hacienda, 278, exp. 4; el inventario de la mercancía embargada de Jorge Rodríguez, Real del aguaje, Sonora, 30 de marzo a 5 de abril de 1718, Archivo Histórico Municipal de Parral, 1718D, G-35m ff. 14v-23v; o el inventario de los géneros dejados por Domingo de Torres, Valle de Opodepe, Sonora, 6 de octubre de 1721, Archivo General de Indias, Contratación 5632, n. 7, ff. 4-7r.

54. Relación del P. José Osorio, Mátape 1690, AGN, Archivo Histórico de Hacienda, 279 , exp. 28.

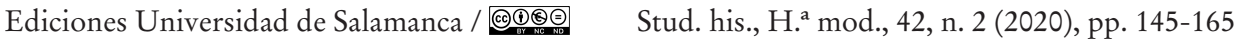


Al fijarse en la procedencia de las mercancías que fluyeron al Noroeste jesuítico, queda muy claro otro fenómeno. La globalización temprana no solo estimuló el intercambio entre diferentes y, en parte, lejanas partes del mundo, sino también hubo un proceso de sustitución de importaciones por producción propia. Su desencadenante fueron los altos costos de transporte en el caso de productos de poco valor, así como las altas tasas de ganancia que garantizaba la venta de ciertos productos de lujo. Así, textiles baratos pronto no se importaban en la Nueva España, sino se produjeron en los obrajes establecidos en Puebla, la Ciudad de México y muchos otros lugares. Su importación, como la de arroz, hubiera encarecido excesivamente su precio. El azúcar, que produjo enormes ingresos a los dueños de las plantaciones esclavistas caribeñas, en la Nueva España no solo se produjo en haciendas en el centro del virreinato sino incluso en varias misiones del noroeste. La sustitución se realizó entonces en varios pasos, desde el Mediterráneo oriental a las islas atlánticas de los portugueses, de allí a Brasil y a las Indias Occidentales, a México y finalmente a la frontera. Un desarrollo particular y fuera de lo común lo muestra el cacao, que siendo una planta originalmente mesoamericana, ya en épocas tempranas su producción se trasladó a Venezuela y Guayaquil.

Es importante señalar que, a diferencia de la globalización actual, la temprana no produjo ninguna homogeneización de los sistemas producción y de trabajo, sino más bien hizo surgir nuevas diferenciaciones, como las mencionadas plantaciones o, también, las misiones como unidades de producción agropecuaria. Pero esto ya sería tema de otro texto.

Lo que sí se daba era una paulatina homogeneización del consumo y de los gustos, convirtiéndose estos con el tiempo en estímulo de la demanda, del comercio en todas sus escalas y, de esta manera, del avance de la globalización temprana. Y esto no solo en el caso de los misioneros, al fin y al cabo un pequeño grupo privilegiado, sino también entre los indios que administraban, los que, por ejemplo, al vestirse cristianamente, requerían de telas importadas. Este cambio inicialmente no se introdujo por gusto, sino fue impuesto por el régimen misional. No obstante estamos aquí frente a una homogeneización de las prácticas corporales (bodily practices), la que Bayly (2004: 12-19) vio como rasgo central de la globalización del siglo XIX. Como muchos otros fenómenos globalizadores, también éste lo encontramos en la América española mucho antes.

\section{BIBLIOGRAFÍA}

Alcalá, L. E. (2007). 'De compras por Europa': Procuradores jesuitas y cultura material en Nueva España. Goya: Revista de Arte, 31, 141-158.

Barnes, Th. C., Naylor, Th. H., y Polzer, Ch. W. (1981). Northern New Spain. A Research Guide. Tucson: The Universisty of Arizona Press. 
BERND HAUSBERGER

EL FLUJO DE MERCANCÍAS A LAS MISIONES JESUITAS

EN EL NOROESTE DE LA NUEVA ESPAÑA

Bayly, Ch. A. (2004). The Birth of the Modern World, 1780-1914. Global Connections and Comparisons. Malden-Oxford: Blackwell.

Bonialian, M. (2016). La «ropa de la China» desde Filipinas hasta Buenos Aires. Circulación, consumo y lucha corporativa, 1580-1620. Revista de Indias, 76(268), 641-672.

Bonialian, M. (2017). Comercio y atlantización del Pacífico mexicano y sudamericano: la crisis del lago indiano y del Galeón de Manila, 1750-1821. América Latina en la Historia Económica, 24(1), 7-36.

Carmagnani, M. (2012). La organización de los espacios americanos en la Monarquía española (siglos XVI a XVIII). En Ó. Mazín y J. J. Ruiz Ibáñez (eds.), Las Indias Occidentales. Procesos de incorporación territorial a las monarquias ibéricas (siglos XVI a XVIII) (pp. 331-355). México: El Colegio de México, Red Columnaria.

Carpio-Penagos, C. U. del (2014). Producción y comercio de tabaco en Centroamérica a fines del período colonial. LiminaR, 12(2),195-208.

Corona Páez, S. A. (2010). El Colegio de los jesuitas de Santa María de las Parras, Sustentabilidad de un instituto educativo a partir de le economía vitivinícola (siglos XVII y XVIII). En F. Duhart y S. A. Corona Páez, Vinos de América y de Europa. Catorce miradas desde las ciencias del hombre (pp. 99-121). París: Éditions Le Mansuscrit.

del Río, I. (1980), Sonora y la ocupación española de la Baja California. Memorias del Simposio de Historia de Sonora, 5, 71-91.

Diccionario de autoridades, 6 vols. Madrid, Real Academia Española, 1726-1738, https:// www.rae.es/recursos/diccionarios/diccionarios-anteriores-1726-1996/diccionariode-autoridades (consultado el 14 de mayo de 2020).

Esteyneffer, J. de (1732). Florilegio medicinal de todas las enfermedades, sacado de varios, $y$ clasicos authores, para bien de los pobres, y de los que tienen falta de Medicos, en particular para las Provincias remotas, en donde administran los RR.PP. Missioneros de la Compañía de Jesús. Madrid: Manuel Fernández (1. a ed. México 1712).

Fechner, F., y Wilde, G. (2020), «Cartas vivas» en la expansión del cristianismo ibérico. Las órdenes religiosas y la organización global de las misiones. Nuevo Mundo Mundos Nuevos [en línea], https://doi.org/10.4000/nuevomundo.794.

Friedrich, M. (2011). Der lange Arm Roms? Globale Verwaltung und Kommunikation im Jesuitenorden, 1540-1773. Frankfurt a. M.; Campus.

García Bernal, Ma. Cr. (1972). La sociedad de Yucatán (1700-1750). Sevilla: Escuela de Estudios Hispano-Americanos.

Gruzinski, S. (2004). Les quatre parties du monde. Histoire d'une mondialisation. París: Martinière.

Hausberger, B. (1997a). Comunidad indígena y minería en la época colonial. El Alto Perú y el noroeste de México en comparación. Ibero-Amerikanisches Archiv, 23(3/4), 263-312.

Hausberger, B. (1997b). La Nueva España y sus metales preciosos. La industria minera colonial a través de los 'libros de cargo y data' de la Real Hacienda, 1761-1767. Frankfurt a. M.: Vervuert.

Hausberger, B. (2000). Für Gott und König. Die Mission der Jesuiten im kolonialen. Viena/ Munich: Verlag für Geschichte und Politik/Oldenbourg.

Ediciones Universidad de Salamanca / @@@ Stud. his., H. ${ }^{a}$ mod., 42, n. 2 (2020), pp. 145-165 
Hausberger, B. (2014). El rescate de plata en Sinaloa, mediados del siglo XVIII. En B. Hausberger y A. Ibarra (coords.), Oro y plata en los inicios de la economía global: de las minas a la moneda (pp, 77-98). México: El Colegio de México.

Hausberger, B. (2018). Historia mínima de la globalización temprana. México: El Colegio de México.

Humboldt, A. de (1985). Ensayo politico sobre el Reino de la Nueva España, edición facsimilar de la edición de Paris, 1822. México: Instituto Cultural Helénico/Miguel Ángel Porrúa.

Machuca, Paulina (2013). El arribo de plantas a las Indias Occidentales: el caso del BalsasJalisco a través de las Relaciones geográficas del siglo XVI. Relaciones, 136, 73-114.

MacLeod, M. J. (1973). Spanish Central America: A Socioeconomic History, 1520-1720. Austin: University of Texas Press.

Martínez-Serna, J. G. (2009). Procurators and the Making of the Jesuits' Atlantic Network. B. Bailyn y P. L. Denault (eds.), In Soundings in the Atlantic World. Latent Structures and Intellectual Currents, 1500-1830 (pp. 181-209). Cambridge, Mass.: Harvard University Press.

Nassu, W. (2016). From Chintz to Chita. A Brazilian Textile and the Construction of National Identity. En Textile Society of America's 15th Biennial Symposium Proceedings (pp. 345-352). https://digitalcommons.unl.edu/cgi/viewcontent.cgi?article=19 928 context=tsaconf (consultado 2 de junio de 2020).

Naylor, Th. H., y Polzer, Ch. W. (1989). Pedro de Rivera and the Military Regulations for Northern New Spain, 1724-1729. Tucson: The Universisty of Arizona Press.

Nemnich, Ph. A. (1816). Spanisches Waren-Lexico in drei Abtheilungen. Hamburgo: Börsen-Halle bei Conrad Müller.

Pastor, R. (2002). El repartimiento de mercancías y los alcaldes mayores novohispanos. Un sistema de explotación, de sus orígenes a la crisis de 1810. En W. Borah (coord.), El gobierno provincial en la Nueva España, 1570-1787 (pp. 219-258). 2. ' ed. México: UNAM.

Pearce, A. (2014). The Origins of Bourbon Reform in Spanish South America, 1700-1763. Basingstoke/Nueva York: Palgrave Macmillan.

Perissinotto, Giorgio (1997). Léxico textil californiano del siglo XVIII. R. Barriga Villanueva/P. M. Butragueño (eds.), Varia lingüística y literaria, vol. 1: Lingüística (pp. 451-469). México: El Colegio de México.

Polzer, Ch. W. (1976), Rules and Precepts of the Jesuit Missions of Northwestern New Spain. Tucson, University of Arizona Press.

Sales Colín, O. (2000). El movimiento portuario de Acapulco. El protagonismo de Nueva España en la relación con Filipinas, 1587-1648. México: Plaza y Valdés.

Sánchez Santiró, E. (2013). Hacienda de Nueva España y el primer reformismo fiscal de los Borbones (1720-1755). Alcances y contradicciones. México: Instituto Mora.

Santamaría, Fr. J. (1983). Diccionario de mejicanismos. 4. ${ }^{a}$ ed. corregida y aumentada, México Porrúa.

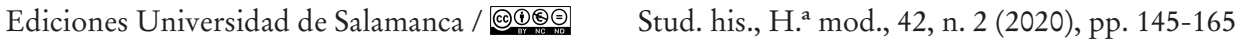


BERND HAUSBERGER

EL FLUJO DE MERCANCÍAS A LAS MISIONES JESUITAS

EN EL NOROESTE DE LA NUEVA ESPAÑA

Segesser, Ph. A. (ed.). (1886). Die Berichte des P. Philipp Segesser aus der Gesellschaft Jesu über seine Mission in Sonora, 1731-1761. Katholische Schweizer Blätter, nueva serie, 2(6-9).

Stobart, J. (2013). Sugar and Spice: Grocers and Groceries in Provincial England, 16501830. Oxford: Oxford University Press.

Suárez Argüello, C. E. (1985). La política cerealera en la economía novohispana. El caso del trigo. México: CIESAS.

Villaseñor y Sánchez, J. A. (1746). Theatro americano, descripción general de los reynos, y provincias de la Nueva España, y sus jurisdicciones. México: viuda de D. Joseph Bernardo de Hogal.

Ediciones Universidad de Salamanca / @@@ Stud. his., H. ${ }^{a}$ mod., 42, n. 2 (2020), pp. 145-165 
